\title{
Regulation of Gluconeogenic Enzymes during the Cell Cycle of Saccharomyces cerevisiae Growing in a Chemostat
}

\author{
By MONICA ARREGUIN DE LORENCEZ AND OTHMAR KÄPPELI*† \\ Institute of Biotechnology, Swiss Federal Institute of Technology, ETH-Hönggerberg, 8093 \\ Zürich, Switzerland
}

(Received 9 January 1987; revised 28 April 1987)

\begin{abstract}
Oscillation of the activities of gluconeogenic enzymes (malate dehydrogenase, phosphoenolpyruvate carboxykinase and fructose-1,6-bisphosphatase) was observed during the cell cycle of chemostat cultures of Saccharomyces cerevisiae. Since ethanol is released by the cells at the beginning of the division cycle, its effect on enzyme expression was determined. Pulsing ethanol to a synchronously dividing yeast culture led to a prolongation of the metabolically active phase as indicated by the course of oxygen uptake and carbon dioxide production rates (concomitant ethanol and glucose assimilation). Enzyme activities also remained elevated as long as ethanol was available to the cells. After a substrate shift from glucose to ethanol during cell division, ethanol was used without a lag phase and enzyme induction increased from the level reached at the point of the substrate change. The data confirmed that the small amount of ethanol produced when the cells begin active reproduction acts as an inducer of gluconeogenic enzymes.
\end{abstract}

\section{INTRODUCTION}

In recent years we have studied the regulation of glucose metabolism in Saccharomyces cerevisiae and related yeasts (for a review see Käppeli, 1986), The aim has been to explain particular features occurring during growth of these yeasts with glucose as the carbon source. The most puzzling property has been aerobic ethanol formation in batch cultures and at high dilution rates in continuous cultures. Further, the expression of several enzymes (gluconeogenic, tricarboxylic acid cycle and glyoxylic acid shunt enzymes) is repressed under conditions of aerobic ethanol formation (Gancedo et al., 1965; Witt et al., 1966; Gancedo \& Schwerzmann, 1976; Polakis et al., 1965; Barnett \& Kornberg, 1960). Also concentrations of mitochondrial cytochromes are lower (Petrik et al., 1983). Since in batch culture experiments the repression of enzyme expression is related to the presence of glucose, the underlying mechanism is referred to as glucose catabolite repression (Magasanik, 1961).

Experiments to investigate regulation, involving continuous culture, dilution rate shift and pulsing (additional glucose or non-carbohydrate carbon source) have indicated two levels of regulation (Petrik et al., 1983). (1) Aerobic ethanol formation is primarily based on limited respiratory capacity. Glucose flux into the cells exceeds the oxidative capacity leading to an overflow reaction on the level of pyruvate with ethanol as the end-product of energy metabolism. (2) Long-term growth of the cells under conditions where ethanol is released, resulting in reduction of enzyme activities.

† Present address: Motor Columbus Engineering Consultants AG, Parkstrasse 27, 5401 Baden, Switzerland. Abbreviations: $\mathrm{MDH}$, malate dehydrogenase; PEPCK, phosphoenolpyruvate carboxykinase; FBPase, fructose1,6-bisphophatase. 
Data gathered from experiments in which substrates other than carbon were limited (Käppeli et al., 1985b) have indicated that the underlying regulatory mechanism is not solely glucose repression but rather a more general effect of reductive metabolism. By analogy with recent research on respiration-impaired Escherichia coli (Hertz \& Bar-Tana, 1986) reductive repression explains the phenotype of the cells with exhausted respiratory capacity. Glucose catabolite repression may be considered as a specific mode of reductive repression.

To understand more details of cellular regulation we have also studied enzyme expression during the division cycle of cells oxidatively assimilating glucose (Käppeli et al., 1985a). Mitochondrial cytochrome contents did not change during the cell cycle. Malate dehydrogenase (MDH), an enzyme that takes part in metabolic pathways besides gluconeogenesis but is strongly induced by ethanol, phosphoenolpyruvate carboxykinase (PEPCK) and fructose 1,6bisphosphatase (FBPase) activities oscillated, with their activities increasing during the budding phase. It was assumed that ethanol, which is produced at the beginning of the division cycle (at a concentration of approximately $200 \mathrm{mg} \mathrm{1}^{-1}$ in a synchronous culture with $30 \mathrm{~g}$ glucose $1^{-1}$ as carbon source), acts as an inducer for gluconeogenic enzymes. The immediate effect on expression can be explained by the active biosynthetic state the cells are in at the time ethanol is produced.

To elucidate the function of ethanol, its concentration was increased by pulsing additional ethanol to the culture and by changing the carbon source from glucose to ethanol at particular points of the cell cycle. The effect of such manipulations on overall metabolic activity and the activities of MDH, PEPCK and FBPase were determined in order to obtain more information on the role of ethanol as an inducer.

\section{METHODS}

Organism. Saccharomyces cerevisiae strain H1022 (ATCC 32167) was used in all experiments.

Medium and culture conditions. A chemically defined medium was used (Käppeli et al., 1985a) with glucose and ethanol as carbon sources. The yeast was grown in a chemostat. Synchronization of the division cycle occurred spontaneously (Käppeli et al., 1985a) at a dilution rate $(D)$ of $0.15 \mathrm{~h}^{-1}$, i.e. when glucose was metabolized by respiration. Growth conditions and equipment were identical to those described by Rieger et al. (1983) and Käppeli et al. $(1985 a)$.

Pulse and shift methodology. Absolute ethanol was injected with a sterile syringe through one of the membranecovered sample ports of the bioreactor to a final concentration of $2.3 \mathrm{~g} \mathrm{l}^{-1}$. During experiments samples were collected at $15 \mathrm{~min}$ intervals. Substrate shifts were effected without interrupting the continuous feed by using two different supply vessels, either of which could be connected to the feeding pump. One vessel contained medium with $3 \%(\mathrm{w} / \mathrm{v})$ glucose as the carbon source; the other contained the same medium with $2.3 \%(\mathrm{w} / \mathrm{v})$ ethanol as carbon source.

Gas turnover rates. The specific oxygen uptake and carbon dioxide production rates were calculated from the data provided by a gas analyser (Bioengineering AG, Wald, Switzerland) connected to the air outlet of the bioreactor, and were based on an inert gas balance.

Sampling. Samples were withdrawn with a syringe by inserting the needle into the reactor through a membrane.

Determination of glucose, biomass and ethanol. For measurement of biomass, $10 \mathrm{ml}$ of culture was centrifuged at $2000 \mathrm{~g}$ for $5 \mathrm{~min}$. The sediment was washed twice with distilled water and then dried to constant weight at $105^{\circ} \mathrm{C}$. Glucose was determined in a glucose analyser (YSI, Yellow Springs, Ohio, USA) with a detection limit of $100 \mathrm{mg} \mathrm{l}^{-1}$. Ethanol was determined enzymically using a test kit from Boehringer.

Preparation of cell-free extracts. Cells (3-5 g wet wt) collected from the bioreactor were centrifuged and washed with $50 \mathrm{~mm}$-potassium phosphate buffer, $\mathrm{pH} 7 \cdot 2$. The sediment was resuspended in the same buffer together with $25 \mathrm{ml}$ glass beads $(0.25-0.5 \mathrm{~mm}$ diameter). The suspension was ground twice for $30 \mathrm{~s}$ using a handmixer equipped with a notched disk. The extract was filtered through a glass frit G2 in order to separate the beads. The crude extract was obtained after centrifugation at $15000 \mathrm{~g}$ at $4{ }^{\circ} \mathrm{C}$ for $10 \mathrm{~min}$.

Enzyme activities. PEPCK, FBPase and MDH were assayed according to Hansen et al. (1976), Gancedo \& Gancedo (1971) and Flury et al. (1974), respectively. Specific activities of PEPCK and FBPase are expressed as nmol substrate converted $\min ^{-1}$ (mg protein) ${ }^{-1}$ and that of $\mathrm{MDH}$ as $\mu$ mol substrate converted $\mathrm{min}^{-1}$ (mg protein $)^{-1}$. Protein was measured with a Bio-Rad protein assay kit, with bovine serum albumin as the protein standard.

All results given are means of at least triplicate measurements. In order to get good reproducibility, a maximum of only two samples were taken per cycle and immediately analysed. The error was within $\pm 15 \%$. 


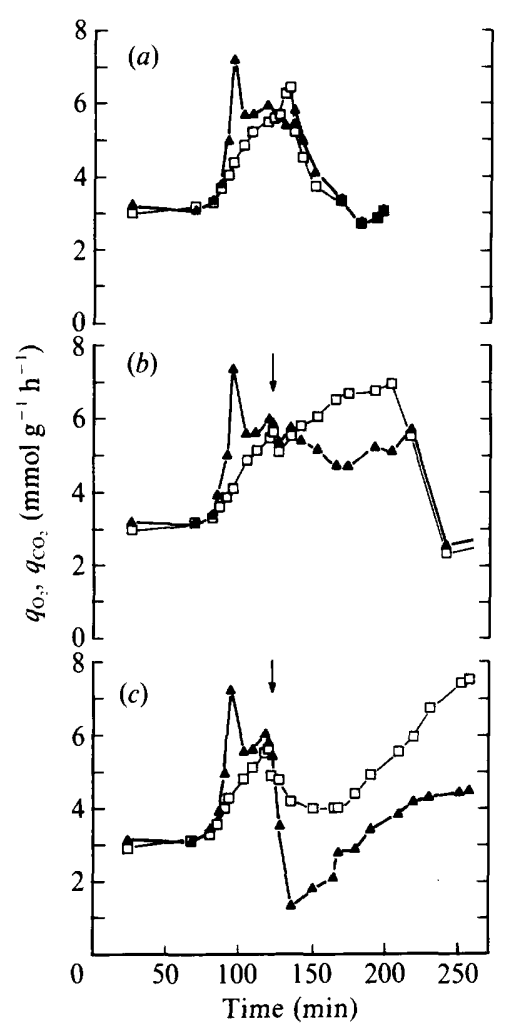

Fig. 1
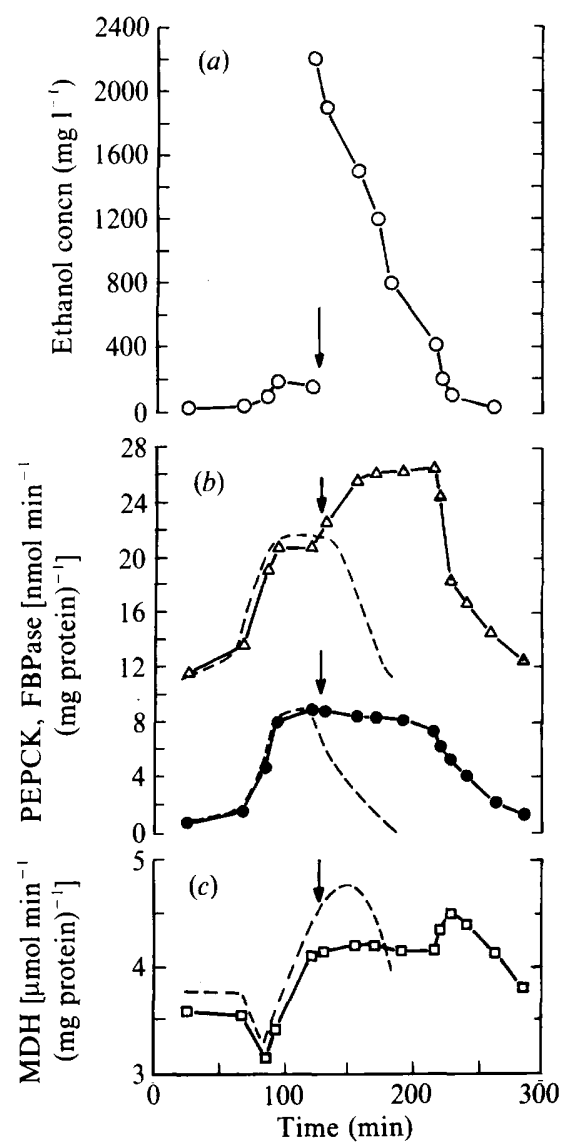

Fig. 2

Fig. 1. Oxygen uptake $(\square)$ and carbon dioxide production $(\boldsymbol{A})$ rates of $S$. cerevisiae. (a) Continuous culture after spontaneous synchronization of the division cycle $\left[D=0.15 \mathrm{~h}^{-1}\right.$; initial glucose concentration $\left(s_{0}\right)=30 \mathrm{~g} \mathrm{l}^{-1}$ ]. (b) Response of gas exchange rates to an ethanol pulse $\left(2 \cdot 3 \mathrm{~g} \mathrm{l}^{-1}\right)$ during the cell cycle (arrow). This led to a prolongation of the period of mixed substrate utilization as compared to the undisturbed synchronous culture. $(c)$ Response of gas turnover rates to a substrate shift from glucose to ethanol during the cell cycle (arrow). Ethanol was assimilated immediately after the shift but at a lower rate compared to the steady state which was reached $4 \mathrm{~h}$ after the shift.

Fig. 2. Effect of an ethanol pulse $\left(2 \cdot 3 \mathrm{~g}^{-1}\right)$ on synchronously dividing cells of $S$. cerevisiae with glucose as carbon source $\left(D=0.15 \mathrm{~h}^{-1} ; s_{0}=30 \mathrm{~g}^{-1}\right)$. (a) Ethanol concentration in the culture medium after the pulse (arrow). (b) Effect of ethanol addition on activities of MDH ( $\square$ ), PEPCK ( $\odot$ ) and FBPase $(\triangle)$. The dashed lines represent the course of the corresponding enzyme activities in an undisturbed synchronous culture (from Käppeli et al., 1985a).

\section{RESULTS}

Synchronously growing cells of $S$. cerevisiae exhibited a characteristic and reproducible pattern of gas exchange rates (Fig. la; Meyer et al., 1985). A distinctive feature was a short period when ethanol was released at the beginning of the cell cycle, which corresponded to a rate of carbon dioxide production that exceeded the rate of oxygen uptake (respiratory quotient $>1$ ). Subsequently, the ethanol was used by the cells.

The activities of MDH, PEPCK and FBPase oscillated during the division cycle, presumably due to induction by ethanol. Therefore, the effect of ethanol was further studied by ethanol pulse and substrate shift experiments. 


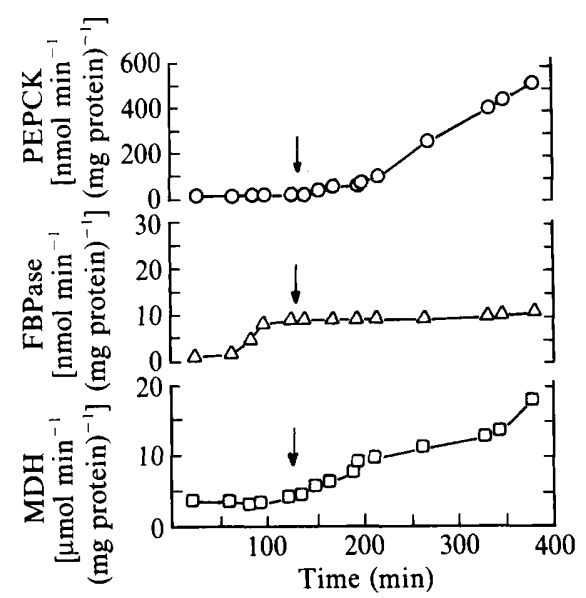

Fig. 3. Shift (arrow) from glucose $\left(30 \mathrm{~g} \mathrm{l}^{-1}\right)$ to ethanol $\left(23 \mathrm{~g} \mathrm{l}^{-1}\right)$ in a continuous culture of $S$. cerevisiae $\left(D=0.15 \mathrm{~h}^{-1}\right)$. Induction of the activities of MDH $(\square)$ and PEPCK $(O)$ continued, whereas FBPase activity $(\triangle)$ was already at its steady state value due to the induction resulting from ethanol released by the cells.

\section{Effect of ethanol on overall metabolism}

When additional ethanol was pulsed to the culture (arrow in Fig. $1 b$ ), an extension of the period of ethanol assimilation was inferred from the course of the gas exchange rates. The values for the respiratory quotient were significantly below unity, indicating concomitant utilization of glucose and ethanol by the cells. When ethanol was exhausted the rates of oxygen uptake and carbon dioxide production dropped to low levels characteristic of cells in the resting phase of the cell cycle.

Rates of oxygen uptake and carbon dioxide production after ethanol pulse and substrate shift (Fig. $1 b, c$ ) indicated that cells were able to assimilate ethanol without a lag phase. However, gas turnover rates were lower than those corresponding to steady state conditions on ethanol. The latter were approached approximately $4 \mathrm{~h}$ after the shift. The respiratory quotient also dropped to values typical of ethanol-assimilating cells (about 0.5 ) immediately after the substrate change.

The dilution rate of $0.15 \mathrm{~h}^{-1}$ selected for the experiments is relatively high for ethanol as substrate $\left(D_{\max }\right.$ approximately $\left.0 \cdot 17 \mathrm{~h}^{-1}\right)$. After a steady state was reached, the residual ethanol concentration was $2 \mathrm{~g} \mathrm{l}^{-1}$ and the rate of oxygen uptake was close to the reported maximum value of $8 \mathrm{mmol} \mathrm{g}^{-1} \mathrm{~h}^{-1}$ (Rieger et al., 1983).

\section{Effect of ethanol on enzyme activities}

Pulsing ethanol to synchronously growing cells significantly affected the activities of MDH, PEPCK and FBPase. The basic temporal pattern of the activities of these enzymes in a nondisturbed synchronous culture underwent remarkable changes (Fig. $2 a, b$ ). The activities of all three enzymes remained elevated as long as ethanol was present, i.e. for an extended period of time as compared to the situation where no ethanol was pulsed. When the ethanol was depleted, the activities of all three enzymes decreased sharply. This indicates that ethanol was responsible for enzyme induction and maintenance of activity.

When the substrate was changed from glucose to ethanol during the cell cycle, further induction of gluconeogenic enzymes was observed (Fig. 3). The initial stages of induction remained the same for all enzymes (poorly visible in Fig. 3 for MDH and PEPCK due to the scale). After not less than $4 \mathrm{~h}$ growth on ethanol steady state values were reached: these were $16 \mu \mathrm{mol} \mathrm{min}^{-1}$ (mg protein) $)^{-1}$, and 672 and $10 \mathrm{nmol} \mathrm{min}^{-1}$ (mg protein) $)^{-1}$, for MDH, PEPCK and FBPase respectively. 


\section{DISCUSSION}

Enzyme synthesis during the division cycle has been investigated in several yeasts (for a review see Elliot \& McLaughlin, 1983). An exhaustive study of about 900 proteins identified eight that appear to be synthesized periodically throughout the cell cycle. All other proteins showed exponential synthesis during the cell cycle. It was suggested that periodic synthesis is rare for proteins and that such proteins may play a direct role in the cell division process. The synthesis of MDH, PEPCK and FBPase clearly shows periodic variation (Käppeli et al., 1985a). The function of these enzymes in the cell division process is related to the metabolism observed during the division cycle.

Von Meyenburg (1969) related the oscillatory pattern of gas exchange rates during continuous culture of $S$. cerevisiae to synchronization of the reproduction cycle. Küenzi \& Fiechter (1969) analysed carbohydrate composition and trehalase activity during the budding cycle of this yeast. Reserve carbohydrates (trehalose and glycogen) were accumulated during the single cell phase and rapid degradation of these reserves began with initiation of the division cycle. The latter coincided with the release of ethanol by the cells.

We have shown that aerobic ethanol formation is based on an overflow reaction on the level of pyruvate when the glycolytic flux exceeds the capacity of respiratory pathways (Petrik et al., 1983; Käppeli et al., 1985b). The data of Küenzi \& Fiechter (1969) indicate that an increased flux during the period of ethanol release is due to the utilization of reserve carbohydrates.

The role of the enzymes investigated can, therefore, be attributed to the utilization of ethanol. The periodic appearance of ethanol is the basis for the periodic synthesis of MDH, PEPCK and FBPase during the division cycle of $S$. cerevisiae. Ethanol acts as an inducer. Its inducing effect becomes particularly evident at initiation of division due to active biosynthesis by the cells.

The substrate shift from glucose to ethanol (Fig. 3) showed that MDH and PEPCK were not fully induced by ethanol produced during the cell cycle. The increased activity lasted approximately one further doubling time. Together with the sharp drop of activities when ethanol disappeared from the culture (Fig. 2) this suggests that the presence of ethanol is a prerequisite for the observed regulation of enzyme activities.

This research was supported by the Swiss National Foundation Grant no. 3.281-0.82.

\section{REFERENCES}

BARnetT, J. A. \& Kornberg, H. L. (1960). The utilization by yeasts of acids of the tricarboxylic acid cycle. Journal of General Microbiology 23, 65-82.

Elliott, S. G. \& Mclaughlin, C. S. (1983). The yeast cell cycle: coordination of growth and division rates. Progress in Nucleic Acid Research and Molecular Biology 28, 143-176.

Flury, U., Heer, B. \& Fiechter, A. (1974). Isoenzyme pattern of malate dehydrogenase during respiratory derepression in Schizosaccharomyces pombe. Archives of Microbiology 97, 141-148.

Gancedo, J. M. \& Gancedo, C. (1971). Fructose-1,6diphosphatase, phosphof ructokinase and glucose-6phosphate dehydrogenase from fermenting and nonfermenting yeasts. Archives of Microbiology 76, 132138.

Gancedo, C. \& Schwerzmann, N. (1976). Inactivation by glucose of phosphoenolpyruvate carboxykinase from Saccharomyces cerevisiae. Archives of Microbiology 109, 221-225.

Gancedo, C., Salas, M. L., Giner, A. \& Sols, A. (1965). Reciprocal effects of carbon sources on the level of an AMP-sensitive fructose-1,6-biphosphatase and phosphofructokinase in yeast. Biochemical and Biophysical Research Communications 20, 15-20.
HANSEn, R. J., Hinze, H. \& Holzer, H. (1976). Assay of phosphoenolpyruvate carboxykinase in crude yeast extracts. Analytical Biochemistry 74, 576584.

HERTZ, R. \& BAR-TANA, R. (1986). Reductive repression in Escherichia coli $\mathrm{K}-12$ is mediated by oxygen radicals. Archives of Biochemistry and Biophysics 250, 54-62.

KÄPPELI, O. (1986). Regulation of carbon metabolism in Saccharomyces cerevisiae and related yeasts. Advances in Microbial Physiology 28, 181-209.

KÄPPEli, O., ARreguiN, M. \& Fiechter, A. (1985a). The respirative breakdown of glucose by Saccharomyces cerevisiae: an assessment of a physiological state. Journal of General Microbiology 131, 14111416.

KäPPEli, O., Geschwend-Petrik, M. \& Fiechter, A. $(1985 b)$. Transient responses of Saccharomyces uvarum to a change of the growth-limiting nutrient in continuous culture. Journal of General Microbiology 131, 47-52.

KüENZI, M. T. \& FIEChTER, A. (1969). Change in carbohydrate composition and trehalase activity during the budding cycle of Saccharomyces cerevisiae. Archives of Microbiology 64, 396-407. 
MagaSaniK, B. (1961). Catabolite repression. Cold Spring Harbor Symposia on Quantitative Biology 26, 249-256.

Meyer, H.-P., KäpPeli, O. \& Fiechter, A. (1985). Growth control in microbial cultures. Annual Review of Microbiology 39, 299-319.

PetrIK, M., KÄPPELI, O. \& FieChTER, A. (1983). An expanded concept for the glucose effect in the Yeast Saccharomyces uvarum: involvement of short- and long-term regulation. Journal of General Microbiology 129, 43-49.

Polakis, E., Bartley, W. \& Meek, G. A. (1965). Changes in the activities of respiratory enzymes during the aerobic growth on different carbon sources. Biochemical Journal 97, 298-302.
RIEGER, M., KäPPELI, O. \& Fiechter, A. (1983). The role of a limited respiration in the incomplete oxidation of glucose by Saccharomyces cerevisiae. Journal of General Microbiology 129, 653-661.

Von MeyenbuRG, H. K. (1969). Energetics of the budding cycle of Saccharomyces cerevisiae during glucose limited aerobic growth. Archives of Microbiology 66, 289-303.

WitT, J., Kronau, R. \& Holzer, H. (1966). Isoenzyme der Malat dehydrogenase und ihre Regulation in Saccharomyces cerevisiae. Biochimica et biophysica acta 128, 63-73. 